\title{
Recognition of Clonogenic Leukemic Cells, Remission Bone Marrow and HLA-identical Donor Bone Marrow by CD8+ or CD4+ Minor Histocompatibility Antigen-specific Cytotoxic T Lymphocytes
}

\author{
Laura M. Faber, * John van der Hoeven, * Els Goulmy, ${ }^{\star}$ Annelies L. Hooftman-den Otter, * \\ Simone A. P. van Luxemburg-Heijs, * Roel Willemze, * and J. H. Frederik Falkenburg * \\ *Laboratory of Experimental Hematology, Department of Hematology, and the ${ }^{\ddagger}$ Department of Immunohematology and Bloodbank, \\ University Medical Center, 2333 AA Leiden, The Netherlands
}

\begin{abstract}
We investigated whether minor histocompatibility ( $\mathrm{mH}$ ) antigen-specific cytotoxic T lymphocytes (CTL) can discriminate between leukemic hematopoietic progenitor cells (leukemic-HPC) from AML or CML patients, the HPC from their remission bone marrow (remission-HPC), and normal HPC from their HLA-identical sibling bone marrow donor (donor-HPC). Specific lysis by CD8 + CTL clones was observed not only of the leukemic-HPC but also of the donorHPC in 3/4 patient/donor combinations expressing $\mathrm{mH}$ antigen HA-1, 3/5 combinations expressing $\mathrm{mH}$ antigen HA2, 2/3 combinations expressing $\mathrm{mH}$ antigen HA-3, and 2/2 combinations expressing $\mathrm{mH}$ antigen $\mathrm{HY}$-A1. In four patient/donor combinations the recognition of the donor-HPC was clearly less than of the leukemic-HPC, indicating differential susceptibility to lysis by these $\mathrm{mH}$ CTL clones. In addition, differential recognition of leukemic-HPC and remission-HPC within seven patients was analyzed. In one patient expressing the HA-2 antigen on the leukemic cells the recognition of the remission-HPC was clearly less than of the leukemic-HPC. One CD4 ${ }^{+}$CTL clone showed specific lysis of the leukemic-HPC from an AML patient and a CML patient as well as of normal remission-HPC and donor-HPC. These results illustrate that in general CD8+ and CD4+ $\mathrm{mH}$ antigen specific CTL clones do not differentially recognize leukemic-HPC and normal-HPC. However, differences in susceptibility to lysis of malignant versus normal cells may contribute to a differential GVL effect. (J. Clin. Invest. 1995. 96:877-883.) Key words: leukemia - clonogenic (leukemic) hematopoietic progenitor cells - differential recognition • graft-versus-host disease • graft-versus-leukemia reactivity
\end{abstract}

Address correspondence to L.M. Faber, MD, Department of Hematology, Building 1, C2-R, University Medical Center, P.O. Box 9600, 2300 RC Leiden, The Netherlands. Phone: 71-262267, FAX: 71-225555.

Received for publication 15 November 1993 and accepted in revised form 4 May 1995.

1. Abbreviations used in this paper: AML, acute myeloid leukemia; BM, bone marrow; BMT, bone marrow transplantation; CML, chronic myeloid leukemia; CTL, cytotoxic T lymphocyte; GVHD, graft-versushost disease; GVL, graft-versus-leukemia; HPC, progenitor cells; $\mathrm{mH}$, minor histocompatibility.

J. Clin. Invest.

(C) The American Society for Clinical Investigation, Inc.

0021-9738/95/08/0877/07 \$2.00

Volume 96, August 1995, 877-883

\section{Introduction}

Allogeneic bone marrow transplantation (BMT) ${ }^{1}$ has been associated with an immune-mediated anti-leukemic effect, the graftversus-leukemia (GVL) effect. T lymphocytes from the donor marrow graft may be responsible for this GVL effect since $T$ cell depletion of the graft is correlated with an increased risk of leukemic relapse after BMT (1-6). Since a correlation has been found between the occurrence of GVHD with a decreased risk of leukemic relapse after BMT $(2,4,7-12)$ it is hypothesized that the donor-derived $\mathrm{T}$ lymphocytes that cause GVHD may also be the mediators of the GVL reactivity. More recently, direct clinical evidence for a GVL effect has been demonstrated by several investigators (13-15). Hematological and cytogenetic remissions after leukocyte transfusion from the original marrow donor for Philadelphia-positive patients with chronic myeloid leukemia (CML) who relapsed after allogeneic BMT have been reported. In the etiology of both GVL and GVHD minor histocompatibility $(\mathrm{mH})$ antigens may play an important role (16-20). In vitro, we have demonstrated that $\mathrm{CD} 8+\mathrm{mH}$ antigen specific cytotoxic $\mathrm{T}$ lymphocyte (CTL) clones generated from patients with GVHD after allogeneic BMT, are capable of antigen-specific lysis of freshly obtained leukemic cells, and of antigen specific growth inhibition of the clonogenic leukemic precursor cells (leukemic-HPC) from unrelated patients $(21,22)$. Furthermore, we have shown that $\mathrm{CD} 8+\mathrm{mH}$ antigen specific CTL clones can recognize $\mathrm{mH}$ antigens on hematopoietic progenitor cells (HPC) (23-25). Recently, we have demonstrated that $\mathrm{mH}$ antigen specific CD4+ CTL clones could be generated from a patient with chronic myeloid leukemia (CML) with acute GVHD grade III-IV after allogeneic BMT (Faber, L.M., S.A.P. van Luxemburg-Heijs, W.F.J. Veenhof, R. Willemze, and J.H.F. Falkenburg, manuscript submitted for publication). As previously illustrated, some $\mathrm{mH}$-specific CTL clones recognize both hematopoietic and non-hematopoietic cells, whereas other reactivities appear to be restricted to cell types of hematopoietic origin (26). In this study we investigated whether $\mathrm{mH}$ antigen specific $\mathrm{CD} 8+$ or CD4+ CTL clones generated from patients with GVHD differentially recognize leukemic-HPC from patients with AML or CML and normal HPC from their HLA genotypically identical sibling donor. Furthermore, we evaluated whether these $\mathrm{mH}$ specific CTL clones can discriminate between leukemic-HPC and the remission progenitor bone marrow cells (remission-HPC), within the same patient with AML. We demonstrate that although in general these $\mathrm{CD} 8+$ and $\mathrm{CD} 4+\mathrm{mH}$ antigen specific $\mathrm{CTL}$ clones do not differentially recognize leukemic-HPC and normal HPC, differences in susceptibility to lysis of malignant versus normal cells can be observed suggesting that in some patients this may result in a specific GVL effect. 


\section{Methods}

Generation of $m H$ antigen-specific CTL clones. CD8+ $\mathrm{mH}$ antigenspecific CTL clones with specific cytotoxicity for the $\mathrm{mH}$ specificity HA-1, HA-2, or HA-3 were generated from patients after allogeneic BMT as previously described $(16,27)$. HA-1 and HA-2-specific recognition is restricted by HLA-A2, HA-3 recognition is restricted by HLAA1. As control effector cells CTL clones with anti-HLA-A2 or antiHLA-A1 specificity (positive controls) or a HLA-B8 restricted $\mathrm{mH}$ antigen specificity (negative control) were used. The frequency of the $\mathrm{mH}$ antigens recognized by the HA-1, HA-2, HA-3 specific CTL clones studied in a random population on the lymphocytes from individuals expressing the relevant class I restriction molecule was $69 \%$ for HA-1, 95\% for HA-2, and $88 \%$ for HA-3 (27). The HLA-A1-restricted HYspecific CTL clone used in this study was generated from a female patient who rejected a T-lymphocyte-depleted bone marrow graft from her HLA-phenotypically identical donor (28).

The CD4+ $\mathrm{mH}$ antigen-specific HLA-DR2 restricted CTL clones, clone 11 was generated from a patient with CML with acute GVHD grade III-IV after allogeneic BMT (Faber, L.M., S.A.P. van LuxemburgHeijs, W.J.F. Veenhof, R. Willemze, and J.H.F. Falkenburg, manuscrip submitted for publication). The second CD4+ CTL clone used, clone $\mathrm{S}$, was generated before HLA-identical allogeneic BMT from the sibling donor directed against the leukemic cells from the recipient (29). Clone $S$, showed HLA-DR2 restricted lysis of the recipient leukemic cells and DR2 positive EBV transformed B cells (EBV-LCL). PHA stimulated $T$ lymphocytes from both recipient and donor were not recognized by this clone.

The CTL clones were cultured in RPMI medium supplemented with $15 \%$ pooled human serum and human recombinant interleukin-2 ( $\mathrm{r}-\mathrm{IL}$ 2) $300 \mathrm{IU} / \mathrm{ml}$ and expanded by weekly restimulation with irradiated, specific $\mathrm{mH}$ antigen positive EBV-LCL plus freshly isolated peripheral blood mononuclear cells (MNC) from random donors. The CTL clones were stored in liquid nitrogen. The day before use the clones were thawed and cultured overnight in RPMI plus $15 \%$ pooled human serum and $\mathrm{rIL}-2300 \mathrm{IU} / \mathrm{ml}$.

${ }^{51} \mathrm{Cr}$ release assay. Standard ${ }^{51} \mathrm{Cr}$ release assays were performed as described previously $(29,30)$. As effector cells, the CTL clones were used; as target cells T lymphocyte populations, leukemic cells, remission bone marrow from the patient, bone marrow from the donor or EBV LCL's were used. Target cells, labelled with ${ }^{51} \mathrm{Cr}$ and effector cells were incubated at various ratio's. To measure spontaneous release of ${ }^{51} \mathrm{Cr}$ target suspensions were analyzed in the absence of effector cells. Maximum release was determined by adding $0.1 \mathrm{ml}$ of the target suspension to $0.1 \mathrm{ml}$ Zaponine solution. The percentage specific lysis obtained in a ${ }^{51} \mathrm{Cr}$ release assay was determined as follows: $100 \% \times$ (experimental release $\mathrm{cpm}$ - spontaneous release $\mathrm{cpm}$ ) / (maximum release $\mathrm{cpm}$ - spontaneous release $\mathrm{cpm}$ ).

Target cells. After informed consent leukemic cells were collected from the bone marrow of patients with AML or CML at diagnosis. Patients with $>95 \%$ morphologically recognizable leukemic cells in their bone marrow were selected. Remission bone marrow was obtained in complete remission from the patients with AML after treatment with daunorubicin and arabinosyl-cytosine (Ara-C) (induction course) and subsequently with high dose Ara-C and amsacrin (consolidation course). (Normal) donor bone marrow was obtained from the HLAidentical sibling donor of patients who were transplanted. The cells were centrifuged over Ficoll Isopaque (density $1.077 \mathrm{~g} / \mathrm{cm}^{3}, 1,000 \mathrm{~g}, 20$ $\mathrm{min}$ ) and the interphase cells were harvested, and cryopreserved in liquid nitrogen. Before use, the cells were thawed, washed twice, and resuspended in RPMI containing $15 \%$ prescreened AB serum.

T lymphocytes were expanded by stimulating $10^{7}$ peripheral blood MNC from patient or donor with $0.2 \%$ phytohemagglutinin (PHA) (Difco Laboratories, Detroit, MI) in RPMI plus $15 \%$ human AB serum for three days. The cells were then washed and further cultured in the absence of PHA in the presence of human rIL-2 $300 \mathrm{IU} / \mathrm{ml}$, for at least three more days before testing.

Stable EBV-LCL were established by in vitro transformation of $10^{7}$ peripheral blood MNC with EBV supernatant. The cells were washed and further cultured in RPMI plus 10\% FCS (GIBCO BRL, Gaithersburg, MD).

Cell-mediated inhibition of clonogenic (leukemic) progenitor cell growth (31). To determine specific reactivity of the anti-mH CTL clones with clonogenic leukemic progenitor cells (leukemic-HPC), remission bone marrow progenitor cells (remission-HPC) and donor bone marrow progenitor cells (donor-HPC) $3.10^{4}$ target cells (leukemic cells or bone marrow cells) in $0.1 \mathrm{ml}$ medium consisting of Iscove's Modified Dulbecco's Medium (IMDM) plus 15\% human AB serum was mixed with irradiated (15Gy) CTL at effector/target (E/T) ratio 1:1. The cell mixture was centrifuged $(1,000 \mathrm{~g}, 15 \mathrm{~s})$ to establish cell-cell contact between CTL and the target cells, and then preincubated for $4 \mathrm{~h}$ at $37^{\circ} \mathrm{C}$. After incubation the cells were resuspended and cultured as a single cell suspension at a concentration of $3.10^{4}$ target cells $/ \mathrm{ml}$ in a $30-\mathrm{mm}$ culture dishes in $1 \mathrm{ml}$ IMDM containing 10\% prescreened human $\mathrm{AB}$ serum, $2 \mathrm{U} / \mathrm{ml}$ erythropoietin (Cilag AG International, Zug, Switzerland), $10 \mathrm{ng} / \mathrm{ml}$ GM-CSF (Sandoz Ltd., Basle, Switzerland), $10 \mathrm{ng} /$ $\mathrm{ml} \mathrm{G-CSF}$ (Amgen, CA), $50 \mathrm{ng} / \mathrm{ml} \mathrm{SCF}$ (Amgen, CA), $25 \mathrm{ng} / \mathrm{ml} \mathrm{IL-}$ 3 (Sandoz Ltd., Basle, Switzerland), 0.47 grams/liter human transferrin (Behringwerke AG, Marburg, Germany) saturated with $\mathrm{FeCl}_{3}, 5.10^{-5}$ $\mathrm{mol} / 1$ mercaptoethanol, and methylcellulose (Methocel $4000 \mathrm{cps}$; Fluka, Freiburg, Germany) at a final concentration of $1.1 \%(\mathrm{wt} / \mathrm{vol})$. The cells were incubated in a fully humidified atmosphere of $5 \% \mathrm{CO}_{2}$ and $37^{\circ} \mathrm{C}$. After $14 \mathrm{~d}$ of culture, the number of leukemic colonies (defined as aggregates of at least 50 undifferentiated cells), CFU-G colonies (defined as aggregates of $>\mathbf{5 0}$ neutrophilic or eosinophilic granulocytes), CFU-M (defined as aggregates $>50$ monocytic cells), and BFU-E colonies (defined as colonies consisting of $>50$ hemoglobinized cells) were scored, using a inverted microscope. The colony growth in the presence of effector cells is expressed as percentage of growth of the number of colonies observed in the untreated (grown in the absence of effector cells) control culture. To control for antigen-nonspecific inhibition of colony growth due to secretion of humoral inhibitory factors into the culture medium, effectors were also plated together with the target cells at the same E/T ratios directly in the semisolid medium, without $4 \mathrm{~h}$ preincubation, to prevent cell-cell contact. The colony growth in the presence of effector cells, without $4 \mathrm{~h}$ preincubation, is expressed as percentage of growth of the number of colonies observed in the untreated (grown in the absence of effector cells) control culture. Specific cell-mediated growth inhibition was determined as follows: 100 - (colony growth in the presence of cell-cell contact/colony growth in the absence of cell-cell contact) $\times 100 \%$. Specific cell-mediated growth inhibition of $<20 \%$ was considered negative. Inhibition of $20-50 \%$ was considered minor inhibition, inhibition of $>50 \%$ positive.

An increased growth of CFU-M colonies was observed when the CD4+ CTL clones, clone 11 and clone S, were used as effector cells, compared to the untreated control cultures. Therefore a conditioned medium was made from both CD4+ clones and added to all culture dishes at a final concentration of $20 \%$ when the corresponding CD4+ CTL clone was used as effector cell.

For cytogenetic analysis of the growing colonies a clonogenic assay of the leukemic cells from patients 8 and 11 was performed. $10^{6}$ cells were cultured under the same conditions as described and were harvested after $7 \mathrm{~d}$ of culture. The methylcellulose was removed by washing with RPMI and the cells were resuspended in the original culture medium without methylcellulose and cultured in suspension in $50 \mathrm{ml}$ tissue culture flasks for 18 hours at $37^{\circ} \mathrm{C}, 5 \% \mathrm{CO}_{2}, 98 \%$ humidity. After colcemid arrest, metaphase spreads were prepared according to standard techniques. At least 30 metaphases were examined for each chromosomal analysis.

\section{Results}

Leukemic cells from seven patients with AML of various subtypes according to the FAB classification and from four patients with CML in chronic phase were analyzed. Only patients ex- 
Table I. Characteristics of the Leukemic Cells and Colony Growth of the Leukemic Precursor Cells per 3.10 $10^{4}$ Plated Cells

\begin{tabular}{|c|c|c|c|c|}
\hline & HLA-Type & FAB-class. & Karyotype & Leuk-HPC \\
\hline 1. & A2 & AML M4/5 & $46 \mathrm{XY} \operatorname{del}(19)(\mathrm{p} 13)$ & 26 \\
\hline 2. & A2 & AML M2 & $46 \mathrm{XY}$ trisomie 10 & 36 \\
\hline 3. & A1, B8 & AML M5 & $46 X Y$ & 286 \\
\hline 4. & $\mathrm{~A} 1, \mathrm{~A} 2, \mathrm{~B} 8$ & CML CP* & $46 \mathrm{XY} \mathrm{t}(9 ; 22)$ & 118 \\
\hline 5. & $\mathrm{~A} 1, \mathrm{~A} 2, \mathrm{~B} 8$ & CML CP* & $46 X Y \mathrm{t}(9 ; 22)$ & 223 \\
\hline 6. & A2 & CML CP* & $46 \times X \mathrm{t}(9 ; 22)$ & 212 \\
\hline 7. & A1, B8 & AML M5 & $46 X Y$ & 383 \\
\hline 8. & $\mathrm{~A} 2$ & AML M2 & $46 X X \mathrm{t}(8 ; 21)$ & 366 \\
\hline 9. & $\mathrm{~A} 2$ & AML M0 & $46 \mathrm{XX}$ & 80 \\
\hline 10. & $\mathrm{~A} 2, \mathrm{DR} 2$ & AML M2 & $46 X Y$ & 149 \\
\hline 11. & $\mathrm{DR} 2$ & CML CP* & $46 \mathrm{XX} t(9 ; 22)$ & 353 \\
\hline
\end{tabular}

* Chronic phase. For patient $11,1.10^{4}$ cells were plated in the experiments.

pressing HLA-A1,-A2, and/or HLA-DR2 on their lymphocytes were selected for this study, corresponding with the HLA-restriction element from the $\mathrm{mH}$ antigen-specific CTL clones used. Table I shows the characteristics of the leukemic samples from the 11 patients used. Cytogenetic analysis of the growing colonies from patients 8 and 11 after $7 \mathrm{~d}$ of culture showed that 93\% of the metaphases contained the $t(8 ; 21)$ translocation and $100 \%$ of the metaphases contained the $t(9 ; 22)$ translocation, respectively. Furthermore, the high percentage $(>95 \%)$ of the leukemic cells in the samples used excluded the possibility of a significant contribution of colonies derived from residual normal progenitor cells present in the cell suspension.

Table II shows the specific reactivity of the CD8+ and CD4+ $\mathrm{mH}$ CTL clones with the T lymphocytes or EBV-LCL from the patients and their HLA-identical sibling donors. In general the $\mathrm{mH}$ specific CTL clones did recognize the $\mathrm{T}$ lymphocytes from both the patient and HLA-identical donor expressing the relevant $\mathrm{mH}$ antigen. However in two patient/donor combinations differences in lysis of $\mathrm{T}$ lymphocytes from the patient versus $\mathrm{T}$ lymphocytes from the donor by two CTL clones was observed. The HA-1 and HA- 3 specific CTL clones showed specific lysis of the $T$ lymphocytes from patient 1 and 4 , respectively, but not of the T lymphocytes from their HLAidentical donor, illustrating that the specific $\mathrm{mH}$ antigen was not expressed by the $\mathrm{T}$ lymphocytes from the donors. When $\mathrm{mH}$ antigen-specific lysis of the $\mathrm{T}$ lymphocytes was observed the leukemic cells from the patients and the bone marrow cells from their HLA-identical sibling donor were further tested in the cell-mediated cytotoxicity assays described.

HLA-A2 and HLA-A1 restricted recognition by the $\mathrm{mH}$ specific CTL clones. The HLA-A2 restricted anti-HA-1 and antiHA-2 CTL clone and the HLA-A1 restricted anti-HA-3 and anti-HY CTL clone showed similar cytotoxicity against the leukemic cells from the patients and the normal bone marrow cell from their HLA-identical sibling donor as measured in the ${ }^{51} \mathrm{Cr}$ release assay (Table III). When these CTL clones were further tested in the clonogenic cytotoxicity assay, similar results were observed from the HA-1, HA-3, and HY-A1 specific CTL clones (Table IV). When the leukemic cells from the patient and the normal bone marrow cells from the HLA-identical donor were recognized in the ${ }^{51} \mathrm{Cr}$ release assay, $\mathrm{mH}$ antigenspecific growth inhibition was observed of both the leukemicHPC from the patient and HPC from the HLA-identical donor. Different results were obtained from the HLA-A2 restricted HA-2 specific CTL clone. This CTL clone recognized the HA2 antigen expressed on the $T$ lymphocytes and leukemic cells from patient 1 and 2, and the $T$ lymphocytes and normal bone marrow cells from their HLA-identical donor in the ${ }^{51} \mathrm{Cr}$ release assay. However, in the clonogenic assay the HA-2 specific CTL clone inhibited the leukemic-HPC from patient 1 and 2 , but showed lower inhibition of the HPC from their HLA-identical donor.

In conclusion the HA-1, HA- 2 and HA- 3 specific CTL clones in general recognize both normal and leukemic HPC, but may discriminate between leukemic-HPC from the patient and normal HPC from the HLA-identical sibling donor.

To investigate whether these $\mathrm{mH}$ antigen specific $\mathrm{CTL}$ clones differentially recognize leukemic and normal precursor cells from individual patients with AML (Table I), the leuke-

Table II. Reactivity of $\mathrm{mH}$-specific CTL Clones with Normal Lymphocytes from the Patients and Their HLA Genotypically Identical Donor

\begin{tabular}{|c|c|c|c|c|c|c|c|c|c|c|c|c|}
\hline \multirow[b]{3}{*}{ CTL-clone } & \multicolumn{12}{|c|}{ Patient/HLA-identical donor } \\
\hline & \multicolumn{2}{|c|}{1} & \multicolumn{2}{|c|}{2} & \multicolumn{2}{|c|}{3} & \multicolumn{2}{|c|}{4} & \multicolumn{2}{|c|}{5} & \multicolumn{2}{|c|}{6} \\
\hline & $\mathbf{P}$ & $\mathbf{D}$ & $\mathbf{P}$ & D & $\mathbf{P}$ & $\mathbf{D}$ & $\mathbf{P}$ & D & $\mathbf{P}$ & D & $\mathbf{P}$ & D \\
\hline HA-1 & ++ & -- & ++ & ++ & -- & -- & ++ & ++ & ++ & ++ & -- & -- \\
\hline HA-2 & ++ & + & ++ & ++ & -- & -- & ++ & ++ & ++ & ++ & ++ & ++ \\
\hline HA-3 & -- & -- & -- & -- & ++ & ++ & ++ & -- & ++ & ++ & -- & -- \\
\hline mH-B8 & -- & -- & -- & -- & -- & -- & -- & -- & -- & -- & -- & -- \\
\hline HY-A1 & -- & -- & -- & -- & ++ & ++ & ++ & ++ & $*$ & $*$ & $*$ & $*$ \\
\hline a-A1 & -- & -- & -- & -- & ++ & ++ & ++ & ++ & ++ & ++ & -- & -- \\
\hline a-A2 & ++ & ++ & ++ & ++ & -- & -- & ++ & ++ & ++ & ++ & ++ & ++ \\
\hline
\end{tabular}

Specific lysis of PHA stimulated T lymphocytes from the patients $(P)$, generated from remission bone marrow cells of the AML patients and from the leukemic bone marrow cells of the CML patients, and from their HLA genotypically identical sibling donor $(D)$ in a ${ }^{51} \mathrm{Cr}$ release assay at $\mathrm{E} / \mathrm{T}$ ratio 3:1. (-) 0-10\% lysis; (+) 10-25\% lysis; (++) 25-100\% lysis; *not tested. The anti-HLA-A1 and anti-HLA-A2 CTL clones were used as positive controls (specific lysis $>25 \%$ ). The HLA-B8 restricted $\mathrm{mH}$ specific CTL clone was used as negative control (specific lysis < $10 \%$ ). 
Table III. Specific Lysis of the Leukemic Cells from the Patients and of the Normal Bone Marrow Cells from Their HLA Genotypically Identical Sibling Donor

\begin{tabular}{|c|c|c|c|c|c|c|c|c|c|c|c|c|}
\hline \multirow[b]{3}{*}{ CTL-clone } & \multicolumn{12}{|c|}{ Patient/HLA-identical donor } \\
\hline & \multicolumn{2}{|c|}{1} & \multicolumn{2}{|c|}{2} & \multicolumn{2}{|c|}{3} & \multicolumn{2}{|c|}{4} & \multicolumn{2}{|c|}{5} & \multicolumn{2}{|c|}{6} \\
\hline & $\mathbf{P}$ & D & $\mathbf{P}$ & D & $\mathbf{P}$ & D & $\mathbf{P}$ & D & $\mathbf{P}$ & D & $\mathbf{P}$ & D \\
\hline HA-1 & 35 & -2 & 50 & 61 & * & $*$ & 35 & 39 & 57 & 29 & $*$ & * \\
\hline HA-2 & 20 & 26 & 39 & 51 & * & * & 21 & 29 & 70 & 35 & 24 & 36 \\
\hline HA-3 & $*$ & $*$ & $*$ & $*$ & 13 & 30 & 30 & -4 & 92 & 51 & $*$ & * \\
\hline HY-A1 & * & * & $*$ & * & 25 & 27 & 35 & 46 & $*$ & $*$ & * & $*$ \\
\hline
\end{tabular}

Specific lysis of the leukemic cells from the patients $(P)$ and of the normal bone marrow cells from their HLA genotypically identical sibling donor $(D)$ was measured using a standard ${ }^{51} \mathrm{Cr}$ release assay in duplicate at $\mathrm{E} / \mathrm{T}$ ratio 3:1. Data are expressed as percentage specific lysis. ${ }^{*}$ Data not applicable because the restriction element was not present. The anti-HLA-A1 and anti-HLA-A2 CTL clones (data not shown) were used as positive controls (specific lysis $>25 \%$ ), the HLA-B8 restricted $\mathrm{mH}$-specific CTL clone as a negative control (specific lysis $<10 \%$ ).

mic-HPC and the remission-HPC from the same patient was further tested in the clonogenic cytotoxicity assay when $\mathrm{mH}$ antigen-specific lysis of the $T$ lymphocytes was observed. In general $\mathrm{mH}$ antigen-specific growth inhibition was observed of both the leukemic-HPC and remission-HPC (Table V). Different results were obtained from the HLA-A2 restricted anti-HA2 specific CTL clone. This CTL clone recognized the HA-2 antigen expressed on the $\mathrm{T}$ lymphocytes, the leukemic cells and remission bone marrow from patients $1,2,8,9$, and 10 in the ${ }^{51} \mathrm{Cr}$ release assay (data not shown). HA-2 specific growth inhibition by this CTL clone was observed of both the leukemic-HPC and remission-HPC from patients 2,8,9, and 10 . However, the HA2 specific CTL clone inhibited the leukemic-HPC, but repeatedly not the remission-HPC from patient 1 (the experiment was repeated three times at different days), indicating differential susceptibility to lysis by this CTL clone (Table V).

In conclusion from the four tested $\mathrm{CD} 8+\mathrm{mH}$ specific $\mathrm{CTL}$ clones only one CTL clone, the HA-2 specific CTL clone discriminated between leukemic-HPC cells and remission-HPC from one patient.

$D R-2$ restricted recognition by the CD4+CTL clones. The two DR-2 restricted CTL clones, clone 11 and clone $S$ recognized the EBV-LCL from AML patient 10 (Table VI). In a ${ }^{51} \mathrm{Cr}$ release assay these two CTL clones showed no specific lysis of the leukemic cells and remission bone marrow (remission-BM) from patient 10 . The low specific lysis of the leukemic cells from patient 10 could not be explained by a low DRexpression of these leukemic cells, since the DR expression was high as measured by FACS analysis. However when the CTL clone 11 was further tested in the cell-mediated clonogenic assay $\mathrm{mH}$ antigen specific growth inhibition was observed of both the leukemic-HPC and the remission-HPC from patient 10. No differential recognition by this CTL clone was observed. Clone S showed no or only minor specific growth inhibition of the leukemic-HPC and remission HPC from patient 10 in the clonogenic assay. The two DR-2 restricted CTL clones, clone 11 and clone $S$ both recognized the EBV-LCL from patient 11 and her HLA-genotypically identical donor (Table VI). Clone 11 showed low but significant specific lysis of the leukemic cells from patient 11 in the ${ }^{51} \mathrm{Cr}$ release assay in three separate experiments $(19 \pm 4 \%)$. This was probably in part due to the relatively low expression of class II molecules on the CML cells $(<50 \%)$. When this CTL clone was further tested in the cell-mediated clonogenic assay $\mathrm{mH}$ antigen specific growth inhibition was observed of both the leukemic-HPC and the donor-HPC from patient 11 . Clone S, the CTL clone that recognized the EBV-LCL from patient 11 and donor 11, and showed minor recognition of the leukemic cells from patient 11 in the

Table IV. HLA-A1 and HLA-A2 Restricted Growth Inhibition of Clonogenic Leukemic Precursor Cells from the Patients and of the Hematopoietic Progenitor Cells from Their HLA Genotypically Identical Sibling Donor

\begin{tabular}{|c|c|c|c|c|c|c|c|c|c|c|c|c|}
\hline \multirow[b]{3}{*}{ CTL-clone } & \multicolumn{12}{|c|}{ Patient/HLA-identical donor } \\
\hline & \multicolumn{2}{|c|}{1} & \multicolumn{2}{|c|}{2} & \multicolumn{2}{|c|}{3} & \multicolumn{2}{|c|}{4} & \multicolumn{2}{|c|}{5} & \multicolumn{2}{|c|}{6} \\
\hline & $\mathbf{P}$ & D & $\mathbf{P}$ & D & $\mathbf{P}$ & D & $\mathbf{P}$ & D & $\mathbf{P}$ & D & $\mathbf{P}$ & D \\
\hline HA-1 & 80 & 17 & 80 & 83 & $*$ & $*$ & 95 & 87 & 76 & 85 & * & $*$ \\
\hline HA-2 & 60 & 31 & 88 & 49 & $*$ & $*$ & 58 & 54 & 69 & 65 & 50 & 53 \\
\hline HA-3 & $*$ & $*$ & $*$ & $*$ & 75 & 71 & 99 & 1 & 94 & 99 & $*$ & * \\
\hline HY-A1 & $*$ & $*$ & $*$ & $*$ & 73 & 86 & 99 & 99 & $*$ & $*$ & $*$ & $*$ \\
\hline
\end{tabular}

HLA-A1 and HLA-A2 restricted $\mathrm{mH}$ specific growth inhibition of clonogenic leukemic precursor cells from patients with AML or CML $(P)$ and of normal hematopoietic precursor cells (BFU-E + CFU-GM) from their HLA-identical donor (D). E/T ratio 1:1 is shown. Similar results were obtained at E/T ratio's 0.3:1 and 0.1:1, respectively. The anti-HLA-A1 and anti-HLA-A2 CTL clones were used as positive controls (specific cell mediated colony growth inhibition $>50 \%$ ), the HLA-B8 restricted $\mathrm{mH}$ specific CTL clone as a negative control (specific cell-mediated colony growth inhibition $<20 \%$ ). 
Table V. HLA-A1 and HLA-A2 Restricted Growth Inhibition of the Clonogenic Leukemic Progenitor Cells and the Remission Hematopoietic Progenitor Cells from the Same Patient

\begin{tabular}{|c|c|c|c|c|c|c|c|c|c|c|c|c|c|c|}
\hline \multirow[b]{3}{*}{ CTL-clone } & \multicolumn{14}{|c|}{ Patient } \\
\hline & \multicolumn{2}{|c|}{1} & \multicolumn{2}{|c|}{2} & \multicolumn{2}{|c|}{3} & \multicolumn{2}{|c|}{7} & \multicolumn{2}{|c|}{8} & \multicolumn{2}{|c|}{9} & \multicolumn{2}{|c|}{10} \\
\hline & $\mathbf{L}$ & $\mathbf{R}$ & L & $\mathbf{R}$ & L & $\mathbf{R}$ & L & $\mathbf{R}$ & L & $\mathbf{R}$ & L & $\mathbf{R}$ & L & $\mathbf{R}$ \\
\hline HA-1 & 80 & 57 & 80 & 96 & * & * & * & * & 2 & 9 & 1 & 30 & 4 & 1 \\
\hline HA-2 & 60 & 1 & 88 & 80 & $*$ & $*$ & $*$ & $*$ & 72 & 55 & 78 & 74 & 53 & 89 \\
\hline HA-3 & $*$ & $*$ & $*$ & $*$ & 75 & 75 & 64 & 58 & $*$ & $*$ & $*$ & $*$ & $*$ & * \\
\hline HY-A1 & $*$ & * & * & * & 73 & 90 & 70 & 98 & $*$ & $*$ & $*$ & $*$ & $*$ & * \\
\hline
\end{tabular}

Growth inhibition of clonogenic leukemic precursor cells (L) and hematopoietic progenitor cells in remission (R) from the same AML patient by the HLA-A1, HLA-A2 and HLA-DR2 restricted $\mathrm{mH}$ specific CTL clones. E/T ratio 1:1 is shown. Similar results were obtained at E/T ratio's 0.3:1 and 0.1:1, respectively. *Data not applicable because the restriction element was not present. The anti-HLA-A1 and anti-HLA-A2 CTL clones were used as positive controls (specific cell mediated colony growth inhibition $>50 \%$ ), the HLA-B8 restricted mH specific CTL clone as a negative control (specific cell-mediated colony growth inhibition $<20 \%$ ).

${ }^{51} \mathrm{Cr}$ release assay $(14 \pm 5 \%, n=3)$. However, this clone did not show specific growth inhibition of the leukemic-HPC and donor-HPC from patient 11 in the cell-mediated clonogenic assay.

\section{Discussion}

In allogeneic bone marrow transplantation, clinical observations have indicated an antileukemic effect of donor-derived $\mathrm{T}$ lymphocytes, the GVL effect $(2,4,32,33)$. An association has been found between the occurrence of GVHD and GVL reactivity, although clinical observations and animal studies have indicated that GVL may exist in the absence of GVHD $(2,32-36)$. Several studies have suggested that both CD8+ and CD4+ T lymphocytes are involved in GVHD and GVL reactivity and may recognize polymorphic antigens in the context of HLAclass I and class II molecules, respectively, that are processed by the recipient cells (37-46). Previously, we have shown that CTL clones directed against $\mathrm{mH}$ antigens generated from patients with GVHD after allogeneic BMT, are capable of antigen-specific lysis in vitro of freshly obtained leukemic cells, and of antigen-specific growth inhibition of the leukemic progenitor cells from unrelated patients $(21,22)$. These experiments support the hypothesis that alloreactive CTL clones directed against polymorphic antigens presented by recipient cells can contribute to the anti-leukemic effect.

Here, we investigated whether leukemic cells from AML or CML patients and normal (progenitor) bone marrow cells obtained in remission or from their HLA-identical sibling donor can show differential susceptibility to lysis by $\mathrm{mH}$ CTL clones. From the $4 \mathrm{CD} 8+$ and 2 CD4+ CTL clones tested three $\mathrm{mH}$ specific CTL clones, the HA-1, the HA-2 and the HA-3 specific CTL clone showed differential recognition of the leukemic-HPC and donor-HPC in 4 of 14 tested patient/donor combinations. In these combinations the leukemic-HPC were recognized by the $\mathrm{mH}$ specific CTL clones and the normal HPC from the HLAidentical donor were not recognized. Only one $\mathrm{mH}$ specific CTL clone, the HA-2 specific CTL clone showed differential recognition of the leukemic-HPC and remission-HPC from one of the five patients. In this patient 1, expressing the HA-1 and HA-2 antigen on the leukemic-HPC the susceptibility to lysis of the remission-HPC by the HA-2 specific CTL clone was repeatedly $(n=3)$ much lower than of the leukemic-HPC. This could not be explained by the impaired expression of the HLA restriction molecule because the anti-HLA-A2 CTL clone and the HLA-A2 restricted HA-1 specific CTL clones did recognize the remission-HPC from patient 1 . We recently have demonstrated that low specific lysis of lymphocytic leukemia cells

Table VI. HLA-DR2 Restricted Specific Lysis of Leukemic Cells, Remission Bone Marrow Cells and Normal Bone Marrow Cells from the HLA Genotypically Identical Donor

\begin{tabular}{|c|c|c|c|c|c|c|c|c|c|c|c|}
\hline & \multicolumn{5}{|c|}{ Patient 10} & \multicolumn{6}{|c|}{ Patient/HLA-identical donor 11} \\
\hline & \multicolumn{3}{|c|}{ Lysis ${ }^{51} \mathrm{Cr}$ release assay* } & \multicolumn{2}{|c|}{ Growth inhibition ${ }^{\ddagger}$} & \multicolumn{4}{|c|}{ Lysis ${ }^{51} \mathrm{Cr}$ release assay* } & \multicolumn{2}{|c|}{ Growth inhibition $^{\ddagger}$} \\
\hline & EBV & Leu & Rem-BM & Leuk-HPC & Rem-HPC & EBV patient & Leuk & EBV-donor & Donor-BM & Leuk-HPC & Donor-HPC \\
\hline Clone 11 & 81 & 7 & 10 & 87 & 65 & 72 & 19 & 73 & 9 & 55 & 53 \\
\hline Clone S & 49 & 2 & 9 & 33 & 2 & 34 & 14 & 30 & 2 & 16 & 18 \\
\hline
\end{tabular}

* HLA-DR2 restricted $\mathrm{mH}$ specific lysis of EBV-LCL, leukemic cells (Leuk), remission bone marrow cells (Rem-BM) and donor bone marrow cells (Donor-BM) was measured using a standard ${ }^{51} \mathrm{Cr}$ release assay in duplicate at $\mathrm{E} / \mathrm{T}$ ratio 3:1. Data are expressed as percentage specific lysis. ${ }^{\ddagger} \mathrm{HLA}$ DR2 restricted $\mathrm{mH}$ specific growth inhibition of clonogenic leukemic progenitor cells (Leuk-HPC) from a patient with AML (patient 10) or CML (patient 11) and of remission hematopoietic progenitor cells (Rem-HPC) from patient 10 or normal hematopoietic progenitor cells from the HLAidentical donor (Donor-HPC) of patient 11. E/T ratio 1:1. Both CD4 + CTL clones showed no specific lysis of control patient, HLA-DR2 positive but not expressing the $\mathrm{mH}$ antigen (data not shown). 
by the HA-2 CTL clone could be explained by a low surface expression of these adhesion molecules as compared to targets that were well recognized (21). The recognition by these latter $\mathrm{mH}$ CTL clones could exclude the possibility of a too low surface expression of the adhesion molecules CD11a/CD18.

Since hematopoiesis in patients with AML in remission may be of clonal origin, clinical remission may be the persistence of a preleukemic clone during remission (47-49). To investigate whether a possible preleukemic hematopoiesis of the remissionBM may explain similarities in recognition of remission and leukemic precursor cells, $\mathrm{mH}$ specific recognition of the remission-BM was compared to the recognition of the bone marrow from the HLA-identical sibling donor. From the 3 HLA-identical sibling pairs tested (AML patient 1,2 and 3) in one pair differential recognition was observed (data not shown). The remission-HPC from patient 2 were strongly lysed by the HA2 specific CTL clone, but only minor recognition of the HPC from the HLA-identical sibling donor was observed. Since also from 1 patient the leukemic cells were more susceptible to lysis than the normal HPC, these results may suggest that a preleukemic hematopoiesis of the remission-BM may be the cause of the relatively high lysis of the remission-BM as compared to the donor bone marrow. On the other hand differential susceptibility to lysis by the HA-2 specific clone due to genetic predisposition may a more likely explanation for this phenomena. Since low specific lysis of normal HPC's by the HA-2 CTL clone was also observed by Marijt et al in 2 of 6 normal healthy bone marrow donors this differential susceptibility to lysis may be explained by a genetic difference in HA-2 antigen expression (25).

From the two tested CD4+ CTL clones clone 11 showed specific lysis of the leukemic-HPC from an AML patient and CML patient as well as of normal remission-HPC and donorHPC respectively. Since the specific lysis of these targets was low in the ${ }^{54} \mathrm{Cr}$ release assay these results confirm the high sensitivity of the clonogenic assay as a tool for the study of cellularly defined antigens on HPC's (31). Clone S, the CD4+ CTL clone that recognizes in vitro transformed EBV-LCL from DR2 positive individuals and some (EBV negative) AML samples did not show specific growth inhibition of the leukemicHPC and HPC's from both patients in the clonogenic assay. However this clone did recognize both the leukemic cells and EBV-LCL from the AML patient against whom this CTL clone was generated (29). Since the EBV-LCL from the HLA-genotypically identical donor of this AML patient were also recognized, the antigen recognized by clone $S$ appeared not to be a classic $\mathrm{mH}$ antigen and is still unclear.

From these data we conclude that in general $\mathrm{mH}$ specific CTL clones (CD8+ and CD4+ CTL clones) do not differentially recognize leukemic-HPC and normal HPC. This is in agreement of studies performed in animals indicating that $\mathrm{mH}$ antigen specific CTL do not discriminate between normal and malignant hematopoietic cells (12). The differential susceptibility to lysis of leukemic-HPC from the recipient and the donorHPC in 4 patient/donor combinations by the HA-1, HA-2, or HA-3 specific CTL clones may explain a GVL reactivity after allogeneic BMT. In our experiments recognition of specific target organs involved in GVHD by the mH CTL clones has not been tested. Recently a study has been performed to determine the expression of human $\mathrm{mH}$ antigens on various tissues (26). The minor antigens HA-3, -4, -6, -7, and HY were detected on all tissues tested (PHA-blasts, EBV-LCL, purified T cells, B cells, monocytes, immature thymocytes, skin-derived cultured fibroblasts, keratinocytes, melanocytes, cultured epithelial cells of kidney proximal tubuli and umbilical cord vein derived endothelial cells), but HA-1 and HA-2 could only be demonstrated on cell types of hematopoietic origin. Therefore, both $\mathrm{mH}$ specific CTL clones recognizing $\mathrm{mH}$ expressed to a high extent on leukemic-HPC as compared to normal HPC, and clones recognizing $\mathrm{mH}$ that are only expressed on hematopoietic cells, may be relevant for the suppression of leukemia relapses after allogeneic BMT.

In conclusion, our results indicated that in general $\mathrm{mH}$ specific CTL clones do not differentially recognize leukemic HPC and normal HPC, nor do the leukemic HPC exhibit a differential sensitivity to lysis or growth inhibition that discriminates them from normal hematopoietic cells. However, in a minority of the cases studied, differential susceptibility of leukemic cells over normal hematopoietic cells can be demonstrated. Thus, in some patients such $\mathrm{mH}$-specific CTL clones may contribute to a differential GvL effect.

\section{Acknowledgments}

The authors thank M.E.M. Kraakman for performing EBV-transformation of B cells and Dr. A. Wessels for performing cytogenetic analysis of the growing colonies.

This work was supported by grants from the Dutch Cancer Society (Koningin Wilhemina Fonds) and the J. A. Cohen Institute for Radiopathology and Radiation Protection. J. H. Frederik Falkenburg is a Special Fellow of the Royal Netherlands Academy of Arts and Sciences.

\section{References}

1. Butturini, A., and R. P. Gale. 1989. Clinical trials of T-cell depletion: current controversies, future directions. In Bone Marrow Transplant: Current Controversies. R. P. Gale and R. E. Champlin, editors. Alan R. Liss, Inc, New York. 495-509.

2. Horowitz, M. M., R. P. Gale, P. M. Sondel, J. M. Goldman, J. Kersey, H. J. Kolb, A. A. Rimm, O. Ringden, C. Rozman, B. Speck, R. L. Truitt, F. E. Zwaan, and M. M. Bortin. 1990. Graft-versus-leukemia reactions after bone marrow transplantation. Blood. 75:555-562.

3. Goldman, J. M., R. P. Gale, M. M. Horowitz, J. C. Biggs, R. E. Champlin, E. Gluckman, R. G. Hoffmann, S. J. Jacobsen, A. M. Marmont, P. B. McGlave, H. Messner, A. Rimm, C. Rozman, B. Speck, S. Tura, R. Weiner, and M. Bortin. 1988. Bone marrow transplantation for chronic myelogenous leukemia in chronic phase. Increased risk for relapse associated with T-cell depletion. Ann. Intern. Med. 108:806-814.

4. Barrett, A. J., M. M. Horowitz, R. P. Gale, J. C. Biggs, B. M. Camitta, K. A. Dicke, R. A. Gluckman, R. A. Good, R. H. Herzig, M. B. Lee, A. M. Marmont, T. Masoaka, N. K. C. Ramsey, A. A. Rimm, B. Speck, F. E. Zwaan, and M. M. Bortin. 1989. Marrow transplantation for acute lymphoblastic leukemia: factors affecting relapse and survival. Blood. 74:862-871.

5. Marmont, A. M., M. M. Horowitz, R. P. Gale, K. Sobocinski, R. C. Ash, D. W. van Bekkum, R. E. Champlin, K. A. Dicke, J. M. Goldman, B. Speck, R. S. Weiner, and M. M. Bortin. 1991. T cell depletion of HLA-identical transplants in leukemia. Blood. 78:2120-2130.

6. Apperley, J. F., F. R. Mauro, J. M. Goldman, W. Gregory, C. K. Arthur, J. Hows, W. Arcese, G. Papa, F. Mandelli, D. Wardle, P. Gravett, G. Franklin, G. Bandini, P. Ricci, S. Tura, A. Iacone, G. Torlontano, W. Heit, R. Champlin, and R. P. Gale. 1988. Bone marrow transplantation for chronic myeloid leukaemia in first chronic phase: importance of a graft-versus-leukaemia effect. Br. J. Haematol. 69:239-245.

7. Weiden, P. L., N. Flournoy, E. D. Thomas, R. Prentice, A. Fefer, C. D. Buckner, and R. Storb. 1979. Antileukemic effect of graft-versus-host disease in human recipients of allogeneic-marrow grafts. N. Engl. J. Med. 300:1068-1073.

8. Weiden, P. L., K. M. Sullivan, N. Flournoy, R. Storb, and E. D. Thomas. 1981. Antileukemic effect of chronic graft-versus-host disease: contribution to improved survival after allogeneic marrow transplantation. N. Engl. J. Med. 304:1529-1533.

9. Wagner, J. E., M. Zahurak, S. Piantadosi, R. B. Geller, G. B. Vogelsang, J. R. Wingard, R. Saral, C. Griffin, N. Shah. B. A. Zehnbauer, R. Armbinder, W. Burns, R. Jones, W. Stratford, S. Rowley, A. Yeager, and G. W. Santos. 1992. 
Bone marrow transplantation of chronic myelogenous leukemia in chronic phase: evaluation of risks and benefits. J. Clin. Oncol. 10:779-789.

10. Frassoni, F., M. Sessarego, A. Bacigalupo, P. Strada, M. Repetto, S. Occhini, R. Defferari, and A. Marmont. 1988. Competition between recipient and donor cells after bone marrow transplantation for chronic myeloid leukemia. $B r$. J. Haematol. 69:471-475.

11. Frassoni, F., D. Scarpati, A. Bacigalupa, V. Vitale, R. Corvo, S. Miceli, F. Gualandi, D. Occhini, M. Clavio, and M. T. Van Lint. 1989. The effect of total body irradiation dose and chronic graft-versus-host disease on leukemic relapse after allogeneic bone marrow transplantation. Br. J. Haematol. 73:211216.

12. Truitt, R. L, A, V. LeFever, C. C. Y. Shih, J. M. Jeske, and T. M. Martin. 1990. Graft-vs-leukemia effect. In Graft-vs-Host-Disease: Immunology, Pathophysiology, and Treatment. H. J. Burakoff, H. J. Deeg, I. Ferrara, and K. Atkinson, editors. Dekker, New York. 177-204.

13. Kolb, H. J., J. Mittermueller, C. Clemm, C. Holler, G. Ledderose, G. Brehm, M. Heim, and W. Wilmanns. 1990. Donor leukocyte transfusions for treatment of recurrent chronic myelogenous leukemia in marrow transplant patients. Blood. 76:2462.

14. Porter, D. L., M. S. Roth, C. McGarigle, R. N. James, J. L. M. Ferrara and J. H. Antin. 1994. Induction of Graft-versus-Host disease as immunotherapy for relapse chronic myeloid leukemia. N. Engl. J. Med. 330:100-106.

15. Bär, B. M. A. M., A. Schattenberg, E. J. B. M. Mensink, A. Geurts Van Kessel, T. F. C. M. Smetsers, G. H. J. N. Knops, E. H. P. Linders, and T. De Witte. 1993. Donor leukocyte infusions for chronic myeloid leukemia after allogeneic bone marrow transplantation. J. Clin. Oncol. 11:513.

16. Goulmy, E. 1988. Minor histocompatibility antigens in man and their role in transplantation. Transplant. Rev. 2:29-53.

17. Perreault, C., F. Decary, S. Brochu, M. Gyger, R. Belanger, and D. Roy. 1990. Minor histocompatibility antigens. Blood. 76:1269-1280.

18. Sondel, P. M., J. A. Hank, T. Wendel, B. Flynn, and M. J. Bozdech. 1983. HLA identical leukemia cells and $\mathrm{T}$ cell growth factor activate cytotoxic $\mathrm{T}$ cell recognition of minor locus histocompatibility antigens in vitro. J. Clin. Invest. 71:1779-1783.

19. Goulmy, E., A. Termijtelen, B. A. Bradley, and J. J. van Rood. 1977. Yantigen killing by $\mathrm{T}$ cells of women is restricted by HLA. Nature (Lond.). 266:544-545.

20. Goulmy, E., J. W. Gratama, E. Blokland, F. E. Zwaan, and J. J. van Rood 1983. A minor transplantation antigen detected by MHC-restricted cytotoxic lymphocytes during graft-versus-host disease. Nature (Lond.). 302:159-161.

21. van der Harst, D., E. Goulmy, J. H. F., Falkenburg, Y. M. C. KooyWinkelaar, S. A. P. Luxemburg-Heijs, H. M. Goselink, and A. Brand. 1994 Recognition of minor histocompatibility antigens on lymphocytic and myeloid leukemic cells by cytotoxic T-cell clones. Blood. 83:1060-1066.

22. Falkenburg, J. H., H. M. Goselink, D. van der Harst, S. A. van Luxemburg Heijs, Y. M. Kooy Winkelaar, L. M. Faber, J. de Kroon, A. Brand, W. E. Fibbe, R. Willemze, and E. Goulmy. 1991. Growth inhibition of clonogenic leukemic precursor cells by minor histocompatibility antigen-specific cytotoxic $\mathrm{T}$ lymphocytes. J. Exp. Med. 174:27-33.

23. Voogt, P. J., E. Goulmy, W. E. Fibbe, W. F. Veenhof, A. Brand, and J. H. Falkenburg. 1988. Minor histocompatibility antigen $\mathrm{H}-\mathrm{Y}$ is expressed on human hematopoietic progenitor cells. J. Clin. Invest. 82:906-912.

24. Voogt, P. J., E. Goulmy, W. F. Veenhof, M. Hamilton, W. E. Fibbe, J. J. van Rood, and J. H. Falkenburg. 1988. Cellularly defined minor histocompatibility antigens are differentially expressed on human hematopoietic progenitor cells. $J$. Exp. Med. 168:2337-2347.

25. Marijt, W. A. F., W. F. J. Veenhof, E. Goulmy, R. Willemze, J. J. van Rood, and J. H. F. Falkenburg. 1993. Minor histocompatibility antigen HA-1,-2,4 and HY specific cytotoxic $\mathrm{T}$ cell clones inhibit human hematopoietic progenitor cell growth by a mechanism that is dependent on direct cell-cell contact. Blood. 82:3778-3785

26. de Bueger, M., A. Bakker, J. J. van Rood, F. van der Woude, and E. Goulmy. 1992. Tissue distribution of human minor Histocompatibility antigens. J. Immunol. 149:1788-1794.

27. van Els, C. A., J. D'Amaro, J. Pool, E. Blokland, A. Bakker, P. J. van Elsen, J. J. van Rood, and E. Goulmy. 1992. Immunogenetics of human minor histocompatibility antigens: their polymorphism and immunodominance. Immunogenetics. 35:161-165.

28. Voogt, P. J., W. E. Fibbe, W. A. Marijt, E. Goulmy, W. F. Veenhof, M. Hamilton, A. Brand, F. E. Zwaan, R. Willemze, J. J. van Rood, and J. H. F. Falkenburg. 1990. Rejection of bone-marrow graft by recipient-derived cytotoxic T lymphocytes against minor histocompatibility antigens. Lancet. 335:131-134. 29. Faber, L. M., S. A. P. Van Luxemburg-Heijs, R. Willemze, and J. H. F.
Falkenburg. 1992. Generation of leukemia-reactive cytotoxic T lymphocyte clones from the HLA-identical bone marrow donor of a patient with leukemia. J. Exp. Med. 176:1283-1289.

30. Goulmy, E. 1982. HLA-A-B restriction of cytotoxic T cells. In HLATyping: Methodology and Clinical Aspects. S. Ferrone and B. G. Solheim, editors. CRC Press, Inc, New York. 105-122.

31. Voogt, P. J., W. E. Fibbe, W. F. J. Veenhof, A. Brand, E. Goulmy, J. J. van Rood, and J. H. F. Falkenburg. 1987. Cell-mediated lysis of human hematopoietic progenitor cells. Leukemia. 1:427-431.

32. Fefer, A., K. M. Sullivan, P. Weiden, C. D. Buckner, G. Schoch, R. Storb, and E. D. Thomas. 1987. Graft versus leukemia effect in man: the relapse rate of leukemia is lower after allogeneic than after syngeneic transplantation. Prog. Clin. Biol. Res. 244:401-408.

33. Jones, R. J., R. F. Ambinder, S. Piantadosi, and G. W. Santos. 1991. Evidence of a graft-versus-lymphoma effect associated with allogeneic bone marrow transplantation. Blood. 77:649-653.

34. Schreiber, K. L., and J. Forman. 1990. Effect of graft-versus-host disease on anti-tumor immunity. J. Immunol. 144:2018-2026.

35. Aizawa, S., and T. Sado. 1991. Graft-versus-leukemia effect in MHCcompatible and incompatible allogeneic bone marrow transplantation of radiationinduced, leukemia-bearing mice. Transplantation. 52:885-889.

36. Glass, B., L. Uharek, W. Gassmann, B. Focks, H. Bolouri, H. Loeffler, and W. Ruchholtz. 1992. Graft-versus-leukemia activity after bone marrow transplantation does not require graft-versus-host disease. Ann. Hematol. 64:255-259.

37. Kaminski, E., J. Hows, S. Man, P. Brookes, S. Mackinnon, T. Hughes, O. Avakian, J. M. Goldman, and J. R. Batchelor. 1989. Prediction of graft versus host disease by frequency analysis of cytytoxic $\mathrm{T}$ cells after unrelated donor bone marrow transplantation. Transplantation. 48:608-613.

38. Irschick, E. U., F. Hladik, D. Niederwieser, W. Nussbaumer, E. Hooler, E. Kaminski, and C. Huber. 1992. Studies on the mechanism of tolerance of graftversus-host disease in allogeneic bone marrow recipients at the level of cytotoxic T-cell precursor frequencies. Blood. 79:1622-1628.

39. Champlin, R., W. Ho, J. Gajewski, S. Feig, M. Burnison, G. Holey, K. Greenberg, I. Lee, I. Schmid, and J. Giorgi. 1990. Selective depletion of CD8+ $\mathrm{T}$ lymphocytes for prevention of graft-versus-host disease after allogeneic bone marrow transplantation. Blood. 76:418-423.

40. Deacock, S., A. Schwarer, R. Batchelor, J. Goldman, and R. Lechler. 1992. A rapid limiting dilution assay for measuring frequencies of alloreactive interleukin-2-producing T cells in humans. J. Immunol. Methods. 147:83-92.

41. Sosman, J. A., K. R. Oettel, S. D. Smith, J. A. Hank, P. Fisch, and P. M. Sondel. 1990. Specific recognition of human leukemic cells by allogeneic $T$ cells: II. Evidence for HLA-D restricted determinants on leukemic cells that are crossreactive with determinants present on unrelated nonleukemic cells. Blood. 75:2005-2016.

42. Truitt, R. L. and A. A. Atasoylu. 1991. Contribution of CD4+ and CD8+ $T$ cells to graft-versus-host disease and graft-versus-leukemia reactivity after transplantation of MHC-compatible bone marrow. Bone marrow transplant 8.51-58.

43. Okunewick, J. P., D. L. Kociban, L. L. Machen, and M. J. Buffo. 1991 The role of CD4 and CD8 T cells in the graft-versus-leukemia response in Rauscher murine leukemia. Bone marrow transplant. 8:445-452.

44. Theobald, M., T. Nierle, D. Bunjes, R. Arnold, and H. Heimpel. 1992 Host-specific interleukin-2-secreting donor T-cell precursors as predictors of acute graft-versus-host disease in bone marrow transplantation between HLA-identical siblings. N. Engl. J. Med. 327:1613-1619.

45. Nierle, T., D. Bunjes, R. Arnold, H. Heimpel, and M. Theobald. 1993 Quantitative assessment of posttransplant host-specific Interleukin-2-secreting Thelper cell precursors in patients with and without acute graft-versus-host disease after allogeneic HLA-identical sibling bone marrow transplantation. Blood. 81:841-848.

46. Theobald, M., and D. Bunjes. 1993. Pretransplant detection of human minor histocompatibility antigen-specific naive and memory interleukin-2-secreting T cells within class I major histocompatibility complex (MHC)-restricted CD8+ and class II MHC-restricted CD4+ T-cell subsets. Blood. 82:298-306.

47. Busque, L., and D. G. Gilliland. 1993. Clonal evolution in acute myeloid leukemia. Blood. 82:337-342.

48. Fialkow, P. J., J. W. Singer, W. H. Raskind, J. W. Adamson, R. J. Jacobson, I. D. Bernstein, L. W. Dow, V. Najfeld, and R. Veith. 1987. Clonal development, stem-cell differentiation, and clinical remissions in acute nonlymphocytic leukemia. N. Engl. J. Med. 317:468-473.

49. Fearon, E. R., P. J. Burke, C. A. Schiffer, B. A. Zehnbauer, and B. Vogelstein. 1986. Differentiation of leukemia cells to polymorphonuclear leukocytes in patients with acute nonlymphocytic leukemia. N. Engl. J. Med. 315:1524. 